Journal of

Accident and

Emergency

Medicine 1995

$12,62-63$
Correspondence:

Mr N.A. Frost,

Clinical Research

Fellow, University

Department of

Opthalmology, Bristol

Eye Hospital, Lower

Maudlin Street, Bristol

BSI 2LX, UK

\title{
Iris dialysis and retinal dialysis caused by coin throwing
}

\author{
N.A.FROST, ${ }^{1}$ P.R.CHAUDHURI, ${ }^{1}$ \& T.B.HASSAN $^{2}$
}

${ }^{1}$ Department of Ophthalmology, Leicester Royal Infirmary and ${ }^{2}$ Department of Accident and Emergency, Leicester Royal Infirmary, Leicester

\section{SUMMARY}

A 13-year old boy was hit in the right eye by a coin that was thrown at him. He presented to the accident and emergency (A\&E) department with an oblique corneal abrasion, microscopic hyphaema, iris-ciliary body dialysis, commotio retinae with retinal haemorrhages and a large retinal dialysis. The limited amount of available data in the medical literature suggests that eye injuries as a result of coin throwing are serious and should always be referred to an ophthalmologist for evaluation.

Key words: Coin throwing, eye injuries

\section{CASE REPORT}

A 13-year-old boy presented to the A\&E department. He had been hit in the right eye by a coin that was thrown at him by another boy at school. Although his visual acuity in that eye at presentation was 6/6 it was apparent that he had sustained a serious eye injury. Examination revealed an oblique corneal abrasion, microscopic hyphaema, iris-ciliary body dialysis (Fig. 1.) and inferior commotio retinae (retinal oedema) with a large inferonasal retinal dialysis, the peripheral retina having been avulsed from its attachment at the ora serrata (Fig. 2). Emergency theatre was arranged and the retinal dialysis was successfully treated with cryotherapy. The hyphaema was treated successfully in the conventional manner with bed-rest, topical corticosteroid and mydriatic.

\section{DISCUSSION}

Although the immediate ocular problems were treated successfully there still remains a future risk of retinal detachment and chronic glaucoma, both predisposing to significant visual loss. Limited data are available in the medical literature regarding this

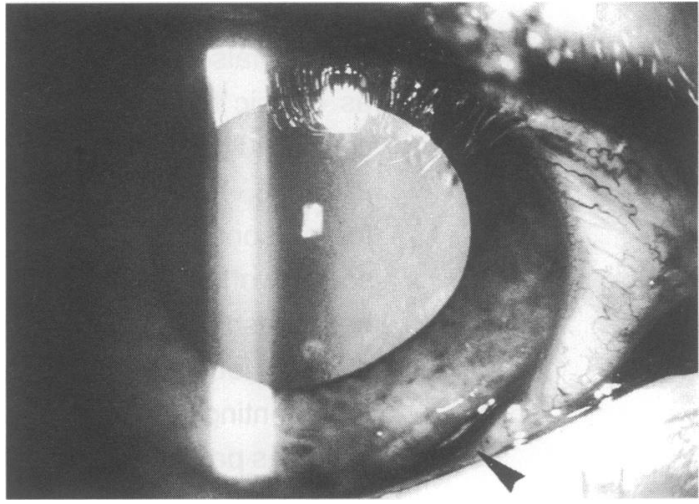

Fig. 1. Coin injury: retroillumination photograph. Note the red reflex (arrowed) peripheral to the iris indicating detachment of the iris and ciliary body from the wall of the globe.

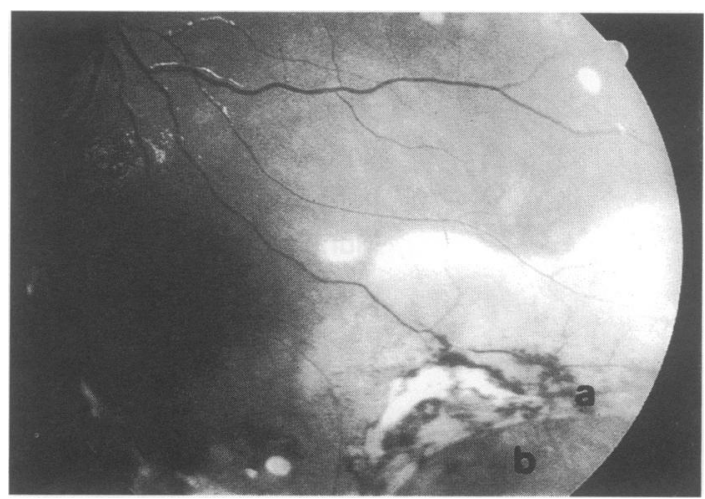

Fig. 2. Coin injury: fundus photograph. Note the oedematous avulsed edge of retina (a) with retinal haemorrhages. The exposed underlying layers are below (b).

type of injury. ${ }^{1}$ There is, of course, a tendency to report only extreme cases. However, the available information suggests that eye injuries as a result of coin throwing are serious and should always be referred to an ophthalmologist for evaluation. 
N.A. Frost et al. Recorded injuries to date include hyphaema, iris dialysis, traumatic cataract, retinal dialysis, retinal detachment and rupture of the globe. Although such incidents seem rare at present these cases raise the question of whether the eye is being chosen as a specific target by those contemplating violence and there is a real possibility of an increase in these events in the future.

\section{ACKNOWLEDGEMENTS}

Photographs by Jan Johnson.

\section{REFERENCES}

1. Frost N.A. \& Hassan T.B. (1993) Serious eye injuries caused by coin throwing. Eye $7,714$. 